\title{
COMÉRCIO ELETRÔNICO: BENEFÍCIOS E ASPECTOS DE SUA APLICAÇÃO
}

\author{
Alberto Luiz Albertin \\ Professor do Departamento de Informática e \\ Métodos Quantitativos da EAESP/FGV \\ E-mail: albertin@eaesp.fgvsp.br
}

RESUMO: O mercado eletrônico, obtido através da aplicação intensiva de Tecnologia de Informação no mercado tradicional, é considerado uma realidade que trará grandes benefícios para as organizações que o considerarem nas suas estratégias e ameaças ainda maiores para as que não o utilizarem. Nesse novo ambiente, o comércio eletrônico, com suas aplicações inovadoras e revolucionárias, é tido como uma das tendências emergentes com maior poder potencial de inovação nas estratégias e nos processos de negócio nos vários setores econômicos. Este artigo tem por objetivo apresentar conceitos relativos a mercado e comércio eletrônico, bem como os benefícios potenciais e aspectos do comércio eletrônico.

ABSTRACT: The electronic market, which is obtained by the intense application of information technology in the traditional market, is considered a reality, which will bring benefits to those organizations which consider it on their strategies, and threaten those which do not use it. In this new environment, the electronic market, with its new and revolutionary applications, is considered as one of the biggest emergent trends with potential to contribute and to innovate business strategies and processes, on all industries. This article presents the concepts about electronic market and commerce, as well as the benefits and aspects of electronic commerce.

PALAVRAS-CHAVE: comércio eletrônico, mercado eletrônico, tendências.

KEY WORDS: electronic commerce, electronic market, trends. 
A economia para a Era da Inteligência em rede é uma economia digital. $\mathrm{Na}$ economia tradicional, o fluxo de informações era físico: dinheiro, cheques, faturas, notas de expedição, relatórios, reuniões face a face, mapas, fotografias etc.'

Na nova economia, a informação em todas as suas formas torna-se digital - reduzida em bits armazenados em computadores e correndo na velocidade da luz através das redes. Utilizando o código binário dos computadores, informações e comunicações tornam-se uns e zeros digitais. No âmbito de Negócio Interconectado em Rede, além da corporação virtual, o comércio precisa se mover para a rede pública.

A nova economia está criando tendências conflitantes, exigindo que as organizações repensem suas missões. Ambientes virtuais e vários outros fatores estão pressionando a estrutura de custo de grandes empresas. O tempo para alcançar o mercado é crítico, quando os produtos têm uma vida competitiva de um ano, um mês, uma semana ou algumas horas, como no caso de produtos financeiros. A inovação, mais que o acesso a recursos ou capital, tem se tornado crítica. Os clientes têm mudado, criando a expectativa de que as empresas precisam prover melhor qualidade, produtos adequados, rapidez, menor preço, com melhor serviço e garantia de responsabilidade social.

Henderson $^{2}$ argumenta que, no mundo competitivo de hoje, o uso efetivo da Tecnologia de Informação (TI) como um elemento da estratégia competitiva é crítico. Na literatura, existe um número considerável de exemplos de como as organizações têm usado a TI para construir e sustentar novos relacionamentos com fornecedores ou clientes e, como resultado, obter uma vantagem competitiva significativa.

Ressalta-se que as empresas não obtêm suas vantagens em virtude apenas da utilização da TI. Muitas vezes, a vantagem é atingida a partir do estabelecimento de uma efetiva parceria, uma vez que a entrega efetiva de produtos e serviços através da TI requer uma parceria, também efetiva, entre os principais atores envolvidos.

As empresas têm usado a TI para, de fato, integrar verticalmente sem serem proprietárias, através do controle de um canal com um intermediário ou fornecedor - ci- tam-se como exemplos o American Hospital Supply Corporation (AHSC) e a American Airlines. Esses mesmos exemplos são utilizados para ilustrar como a TI pode ser utilizada para eliminar canais intermediários e ligar diretamente os clientes finais, simplificando a complexidade dos produtos, aumentando a participação no mercado e expandindo oportunidades para criar relacionamentos de parcerias entre compradores e vendedores. ${ }^{3}$

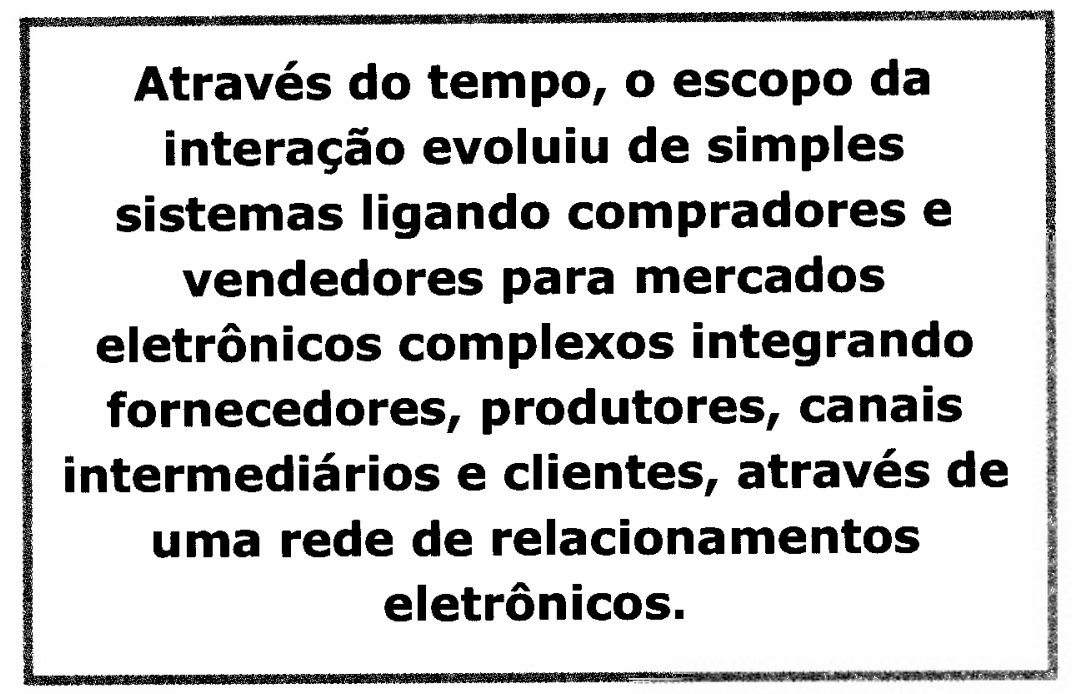

Através do tempo, o escopo da interação evoluiu de simples sistemas ligando compradores e vendedores para mercados eletrônicos complexos integrando fornecedores, produtores, canais intermediários e clientes, através de uma rede de relacionamentos eletrônicos.

A busca dessa nova economia, ou melhor, da forma de se adaptar, sobreviver e obter vantagens nesta nova realidade econômica, tem sido matéria de, pelo lado acadêmico, estudos e pesquisas, e, pelo lado empresarial, elaboração e revisão de estratégias de negócio, definição de estratégias da TI, mudanças de processos internos e externos etc.

\section{MERCADO ELETRÔNICO}

Como definido por Malone, Yates e Benjamin, ${ }^{4}$ o mercado coordena o fluxo de materiais e serviços entre fornecedores e forças de demanda, bem como transações externas entre diferentes indivíduos e empresas. As forças de mercado determinam o projeto, preço, quantidade e cronograma de entrega
1. TAPSCOTT, D. The digital economy: promise and peril in the age of networked intelligence. New York: McGraw-Hill, 1996.

2. HENDERSON, J. C. Plugging into strategic partnerships: the critical IS connection. Sloan Management Review. v.31, n.2, p.7-18, Spring 1990.

3. APPLEGATE L., M., McFARLAN, F. W., MCKENNEY, J. L. Corporate information systems management: text and cases. Boston: Irwin, 1996.

4. MALONE, T. W. YATES, J., BENJAMIN R. I. Electronic markets and electronic v.30, n.5, p.484-97, June 1987 . hierarquies. Communications of $A C M$. 
desejado para um dado produto, que servirão como uma entrada em um outro processo: o comprador de um produto ou serviço compara as muitas possíveis fontes e faz sua escolha baseado na melhor combinação desses atributos.

\section{O mercado eletrônico não é irreal e teórico, ele é de fato inevitável. Sua contínua proliferação e evolução irá alterar toda a nossa economia.}

5. MALONE, T. W., YATES, J., BENJAMIN, R. I. The logic of electronic markets. Harvard Business Review. v.67, n.3, p.166-70, May-June 1989.

6. BAKOS, J. Y. A strategic analysis of electronic marketplaces. MIS Quarterly. v.15, n.3, p.294-310, September 1991.
A hierarquia coordena o fluxo de materiais entre passos adjacentes, controlando e direcionando-o num alto nível na hierarquia gerencial. As decisões gerenciais, não a integração das forças de mercado, determinam o projeto, preço (se relevante), quantidade e cronograma de entrega daqueles produtos de um passo da cadeia de valor adicionado, que são procurados pelo passo seguinte. Os compradores não selecionam o fornecedor dentre um grupo de potenciais fornecedores, eles simplesmente trabalham com um único e predeterminado.

O que define que um produto será tratado pelo mercado ou pela hierarquia é sua complexidade e especificidade. Produtos com baixa complexidade e baixa especificidade são tratados pelo mercado, enquanto produtos com alta complexidade e alta especificidade são tratados pela hierarquia. A tendência é que um número cada vez maior de produtos passem a ser tratados pelo mercado.

A utilização intensa da TI leva ao mercado eletrônico e à hierarquia eletrônica. A coordenação de fluxos de materiais e serviços passa a ser realizada apoiada na tecnologia, ou melhor, por meio dela.

Segundo Malone, Yates e Benjamin, ${ }^{5}$ o mercado eletrônico não é irreal ou teórico, ele é de fato inevitável. Sua contínua proliferação e evolução irá alterar toda a nossa economia. Ele irá afetar negativamente todos os negócios que decidirem não participar dele. Certamente, os executivos têm que analisar suas tendências, porque esse novo mercado está cheio de ameaças para os não- preparados e cheio de oportunidades para os preparados.

Segundo Bakos, ${ }^{6}$ ao utilizar a teoria econômica para entender as implicações estratégicas do mercado eletrônico, é necessário focar suas principais características, especialmente aquelas que o distinguem de outros tipos de investimentos de capital. Nesse contexto, cinco características dos sistemas de mercado eletrônico podem explicar, numa perspectiva econômica, seu potencial estratégico, assim como seus impactos para a estrutura e eficiência dos mercados:

- um sistema de mercado eletrônico pode reduzir os custos dos clientes de obter informações sobre preços e produtos oferecidos por fornecedores alternativos, assim como os custos de fornecedores de comunicar informações sobre seus preços e características de produtos para clientes adicionais;

- os benefícios percebidos por participantes individuais num mercado eletrônico aumentam à medida que organizações se juntam ao sistema;

- os mercados eletrônicos podem impor mudanças significativas de custos para seus participantes;

- os mercados eletrônicos tipicamente requerem grandes investimentos de capital e oferecem substanciais economias de escala e escopo;

- os participantes dos mercados eletrônicos se deparam com incertezas substanciais em relação aos benefícios reais de se juntar a tal sistema. Ocasionalmente, essas incertezas permanecem mesmo depois de uma organização se juntar ao sistema.

Conclui-se que o mercado eletrônico é um fato da vida e que está se tornando mais prevalecente a cada dia. Ele contribui para a realização de um mercado econômico ideal, como um lugar abstrato para trocas com informações completas, onde os custos de transação não são considerados.

Os mercados eletrônicos são caracterizados pelas seguintes facilidades:

- onipresença;

- facilidade de acesso a informação;

- baixo custo de transação.

Assim, os mercados eletrônicos promovem coordenação de atividades de negócio pelas formas de mecanismos de mercado, pela globalização de mercados, por abrir os mercados, pela oferta de acesso mais fácil e 
por substituir outros mecanismos de coordenação, especialmente hierarquias.

A Figura 1 ilustra o mercado eletrônico, com alguns de seus aspectos.

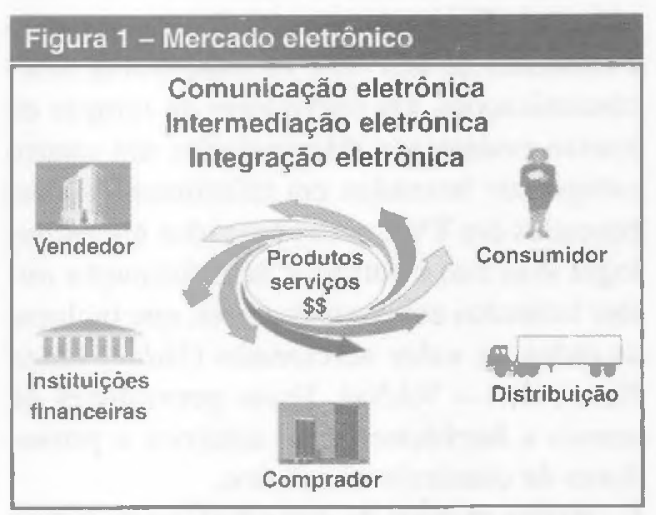

\section{Intermediação e integração eletrônica}

A aplicação da TI no mercado pode ser entendida através dos conceitos de:

- Comunicação eletrônica: troca eletrônica de informação entre duas ou mais partes, que permite que mais informações possam ser comunicadas num mesmo intervalo de tempo (ou a mesma quantidade em menor tempo), com uma diminuição acentuada dos custos e do tempo gasto nos processos, qlém da diminuição da ocorrência de falhas. - Intermediação eletrônica: disponibilizaçăo de informação de fornecedores para clientes e vice-versa, suporte à elaboração de alternativas e sua seleção, que permite o aumento de alternativas que podem ser consideradas nos processos do mercado, aumento da qualidade da alternativa eventualmente selecionada, com redução do custo de todo o processo de seleção de produtos.

- Integração eletrônica: permite que todos os participantes do mercado estejam conectados eletronicamente, permitiudo a efetivação do mercado eletrônico e da hierarquia eletrônica.

Venkatraman e Kambil ${ }^{7}$ definiram que a integração eletrônica é distinta das plataformas comuns de troca eletrônica de dados (Electronic Data Interchange - EDI), assim como dos diferentes tipos de sistemas interorganizacionais (Interorganizational Systems - IOS).

- EDI refere-se à plataforma técnica baseada num conjunto de padrōes estruturados para troca informacional entre participantes num mercado.

- IOS estabelece um conjunto de padrões EDI, seja comum (por exemplo, X12) ou proprietário (por exemplo, sistemas de reserva aérea inicial), para projetar e desenvolver diferentes funcionalidades que interconectam múltiplas organizações. Uma vez com uma categoria particular de IOS, empresas diferentes podem escolher e enfatizar diferentes funcionalidades.

- Integração eletrônica refere-se a escothas estratégicas de empresas para explorar as funcionalidades a fim de desenvolver relacionamentos interorganizacionais e com consumidor para objetivos de negócio específicos. Ela está relacionada com um conjunto de decisões de negócio, que alavanca o novo ambiente tecnológico para obter vantagens de uma empresa específica num mercado. A integração eletrônica, então, é imbuída com as características do sistema de IOS e padrōes técnicos de EDI, mas tem uma orientação de negócio distinta.

Com base na análise do ambiente de integraçăo eletrônica, relacionam-se as seguintes implicações estratégicas:

- Integração eletrônica é mais que troca eletrônica de dados.

- Integração eletrônica é mais que automação de tarefas.

- Integração eletrônica redefine os papéis no mercado.

- O impacto potencial da integraçāo eletrônica nas competências de negócio é variada.

- Efetiva integração eletrônica alavanca a capacidade tecnológica e o conteúdo de informação.

- Estratégias para integração eletrônica compelem gerenciamento efetivo de relacionamentos múltiplos.

\section{Cyberspace}

Ravindran, Barua, Lee e Whinston ${ }^{8}$ definem que cyberspace - a teia mundial de redes de computadores e serviços de informação - é onde as pessoas podem se comunicar interativamente, onde as pessoas podem pedir produtos e serviços, e onde empresas podem realizar transações de negócios com seus fornecedores e instituições financeiras, entre muitas outras possibilidades. A Internet, o backbone dessa rede
7. VENKATRAMAN, N., KAMBHL, A. The check's not in the mail: strategies for electronic integration in tax return filing. Sloan Management Review. v.32, n.2, p.33-43, Winter 1991.

8. RAVINDRAN. S., BARUA, A, LEE, B., WHINSTON, A. B. Strategies for smart shopping in cyberspace. Journal of Organizational Computing and Electronic Commerce. v. $6, \pi .1$, p.33-49, 1996. 
global, iniciou-se como um sistema de comunicações militar e por demanda popular foi aberta para o público através de gateways. Um grande número de provedores está surgindo para oferecer serviços de rede, que permitem a indivíduos e organizações ligarem-se na Internet. Muitos outros querem prover entretenimento, visita a lojas virtuais, compras e serviços de informação, que a Internet é capaz de suportar.

Un dos mais importantes usos das redes mundiais envolverá a jdentificação de fornecedores ótimos para os requisitos de uma empresa.

Os dois tipos de produtos/serviços que podem ser oferecidos nas redes são:

- produtos padronizados e homogêneos, como discos de computadores ou papel de impressora;

- produtos customizados, como maquinaria para fins especiais ou sistemas de software especializados.

Kalakota e Whinston" definem três componentes principais para o estabelecimento de infra-estrutura de Information Superhighway (I-way), conforme apresentado na Figura 2.

Figura 2 - Componentes da infra-estrutura da Information Superhighway

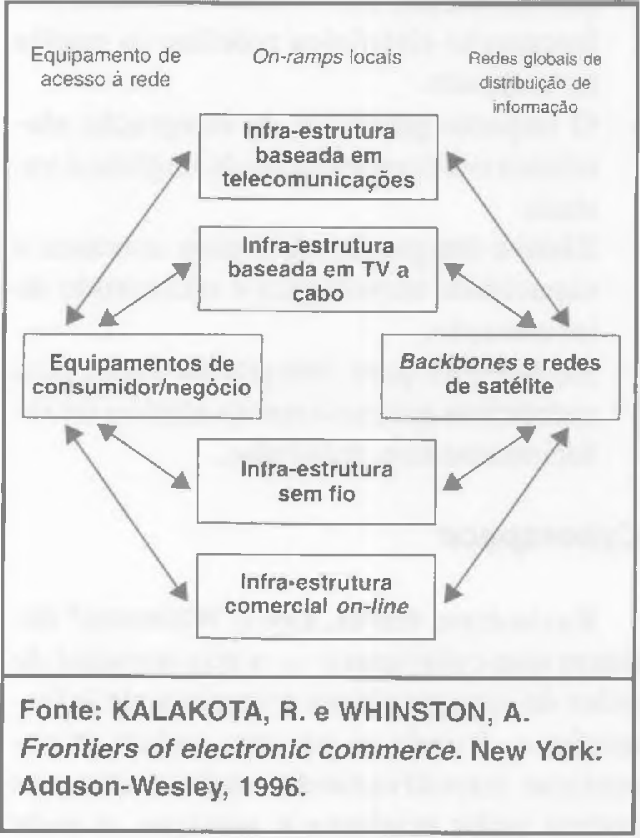

9. KALAKOTA, R., WHINSTON, A. Frontiers of electronic commerce. New York: Addson-Wesley, 1996. é geralmente ignorado nas discussões sobre I-way, mas representa uma categoria crítica,
- Equipamento de acesso de consumidor: a ausência ou o progresso lento dos quais outros segmentos da $I$-way dependem.

- Rotas locais ou de acesso (on-ramps): simplesmente ligações entre negócios, escolas e residências com o backbone de comunicações. Esse componente freqüentemente é chamado de last mile na indústria de telecomunicações. Os provedores de rampas de acesso podem ser diferenciados em quatro categorias: baseados em telecomunicaçōes; baseados em TV a cabo; baseados em tecnologia sem fio; e serviços de informação online baseados em computadores, que incluem as redes de valor adicionado (Value-Added Networks - VANs). Esses provedores de acesso a backbone ligam usuários e provedores de comércio eletrônico.

- Redes globais de distribuição de infor mação: representam a infra-estrutura através de países e continentes. A maioria da infra-estrutura para a $I$-way já existe numa vasta rede de fibra óptica, cabos coaxiais, ondas de rádio, satélites etc.

Ligar todos esses componentes da $I$-way irá requerer um grande investimento de capital em sistemas abertos (equipamentos interoperáveis que utilizam padrỗes comuns) e instalar gateways entre as várias redes. Um requerimento final é a mudança de hardware e software para mover, sem grandes esforços, uma cnormc quantidade de dados numa rede complexa.

Acredita-se que a Internet é o mais bem conhecido componente da infra-estrutura de rede da $l$-way. Atualmente, a Internet (Intercontinental networks) é um sistema de distribuição de informação espalhado por vários países. Sua infra-estrutura muito geral atinge não apenas as aplicações de comércio eletrônico, tais como vídeo on-demand ou home shopping, mas uma grande lista de serviços baseados em computador, tais como $e$ mail, EDI, publicação de informação, recuperação de informação e videoconferência. O ambiente da Internet é uma combinação única de serviço postal, sistema de telefone, pesquisa bibliográfica, supermercado e centro de conversação, que permite às pessoas compartilhar e comprar informaçōes. Essa troca acontece rapidamente, usualmente em questão de segundos, usando tecnologia razoavelmente barata e comumente disponível. A Internet é vista como um protótipo da $I$ way emergente, da qual se tornará um componente. 


\section{COMÉRCIO ELETRÔNICO}

O comércio eletrônico (CE) pode ser definido como sendo a compra e a venda de informações, produtos e serviços através de redes de computadores. ${ }^{10}$

Applegate, Holsapple, Kalakota, Radermacher e Whinston, " afirmam que CE envolve mais do que apenas comprar e vender. Ele inclui todos os tipos de esforços de pré-vendas e pós-vendas, assim como um conjunto de atividades auxiliares, que, por sua vez, incluem novos enfoques para pesquisa de mercado, geração de condução qualificadas de vendas, anúncios, compra e distribuição de produtos, suporte a cliente, recrutamento, relações públicas, operações de negócio, administração da produção, distribuição de conhecimento e transações financeiras. Essas atividades afetam o planejamento estratégico, oportunidades empreendedoras, projeto e desempenho organizacional, leis de negócio e políticas de taxação.

Uma vez que se trabalha junto a este mundo de conhecimento intensivo do $\mathrm{CE}$, é necessário reexaminar os processos de negócio fundamentais e como eles podem ser desempenhados online. As práticas bancárias centrais nẫo têm mudado significativamente nos últimos 300 anos porque os instrumentos financeiros básicos continuam os mesmos - papel-moeda e cheques. Mas como o CE incorpora novas formas de instrumentos financeiros, tais como dinheiro digital e cheques eletrônicos, esperamse grandes mudanças nos bancos.

Segundo Applegate, McFarlan e McKenney, ${ }^{12}$ nos anos 90 o CE está criando uma nova lógica de negócios, sendo possível encontrar numerosos exemplos de uso da TI para ligar diretamente os clientes finais - geralmente eliminando intermediários nos canais de distribuição.

Quando a funcionalidade e a disponibilidade de plataformas de mercado interorganizacional cresce, um número crescente de empresas descobre que elas podem eliminar canais intermediários e trocar produtos e serviços diretamente com os clientes. O CE está sendo utilizado para reduzir a complexidade dos produtos e mercado, enquanto, simultaneamente, aumenta a penetração no mercado. Agregando novo valor adicionado e serviços de informações customizados aos produtos e serviços tradicionais, as empresas podem expandir as oportunidades de vendas por relacionamento, enquanto reduzem os custos e complexidade da oferta de serviços customizados.

Um dos impactos mais interessantes do CE na intermediação é a mudança na estrutura de distribuição de uma indústria, principalmente em relação aos intermediários. Tradicionalmente, estes provêm uma infra-estrutura, tal como uma rede de vendas (lugares físicos como lojas, pessoal especializado etc.), e gerenciam a complexidade do tratamento dos requisitos de clientes. O CE pode substituir algumas das funções tradicionalmente desempenhadas por esses intermediários, permitindo inclusive que surjam novos atores no cenário de competitividade das indústrias.

Kalakota e Whinston ${ }^{13}$ definem que o CE não pode atingir todo o seu potencial como um conceito desintegrado, considerando principalmente cliente-organização, interorganizacional, ou atividades de automação internas e desconectadas. Para as companhias serem completamente efetivas, essas três atividades precisam estar integradas e as aplicações de software correspondentes, desenvolvidas conjuntamente, A Figura 3 apresenta o modelo de CE público e privado.

\section{Figura 3 - Comércio eletrônico privado e público}

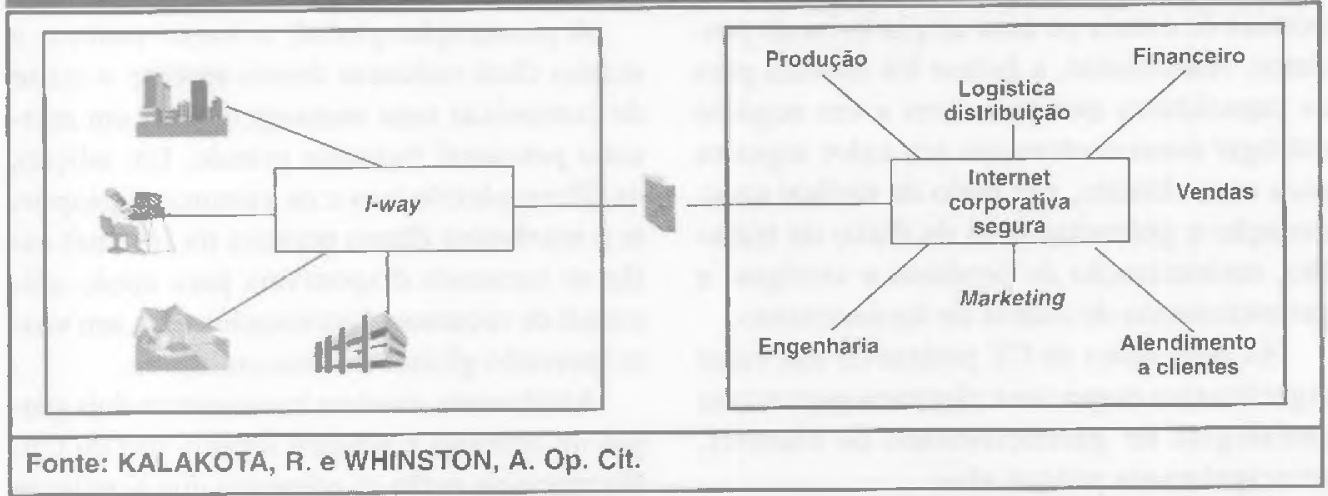

10. KALAKOTA, R., WHINSTON, A. Op. cit.

11. APPLEGATE, L. M. et al. Electronic commerce: building blocks of new business opportunity. Journal of Organizational Computing and Electronic Commerce v.6, n.1. p.1-10, 1996.

12. APPLEGATE L., M., McFARLAN, F. W. McKENNEY, J. L. Op. cit.

13. KALAKOTA, R., WHINSTON, A.Op. cit. 
O CE público é tido como construído na fundação da World Wide Web (WWW) e outras tecnologias sobre as quais empresas, fornecedores e consumidores se ligam nas transações on-line. Uma visão superficial tende a assumir que o CE é restrito exclusivamente a atividades externas da organização, $\mathrm{o} E$ público.

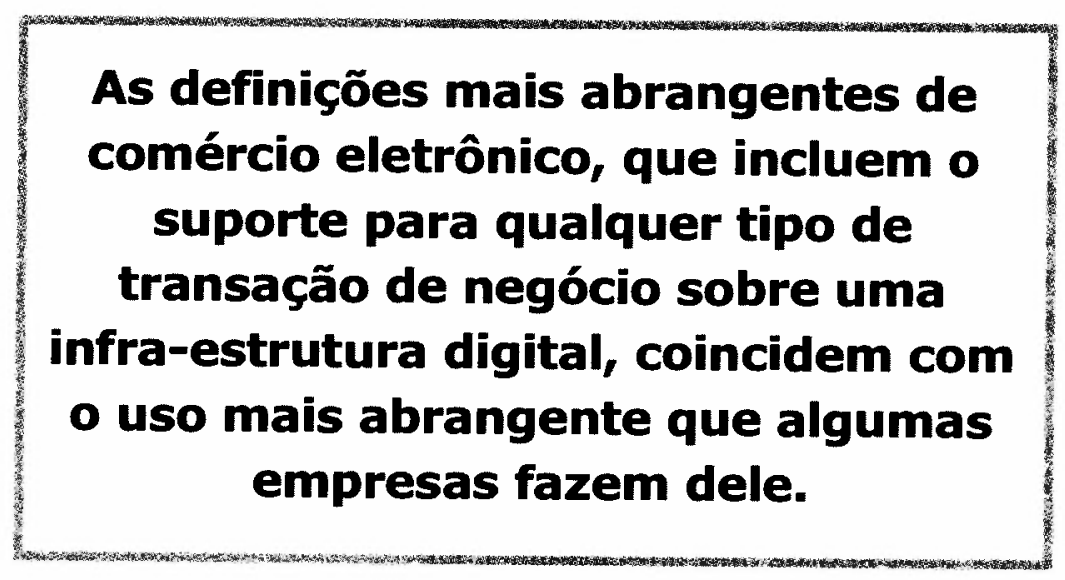

O CE privado é definido como sendo a utilização de comércio eletrônico nos processos e aplicações. Especificamente, define-se comércio interno como utilizando métodos e tecnologias pertinentes para suportar processos de negócio internos entre indivíduos, departamentos e organizações colaboradoras.

As forças de negócio que estão orientando o comércio interno são as forças de mercado econômicas e competitivas. Essas forças estão comandando a reavaliação da importância das redes - computador e comunicações - e seu papel na melhor utilização de informação corporativa na tomada de decisão operacional e analítica.

Para obter melhor desempenho, um negócio precisa desenvolver e sustentar a vantagem competitiva. A vantagem competitiva foi anteriormente baseada nas características estruturais, tais como poder de mercado, economias de escala ou uma ampla linha de produtos. Atualmente, a ênfase foi movida para as capacidades que permitem a um negócio entregar consistentemente um valor superior para seus clientes, por meio de melhor coordenação e gerenciamento de fluxo de trabalho, customização de produtos e serviços, e gerenciamento de cadeia de fornecimento.

As aplicações de CE podem ter um valor significativo como uma alavanca para novas estratégias de gerenciamento de clientes, principalmente porque elas:
- conectam diretamente compradores e vendedores;

- apóiam a troca de informações totalmente digitais entre eles;

- eliminam os limites de tempo e lugar;

- apóiam a interatividade e então podem adaptar-se dinamicamente ao comportamento do cliente;

- podem ser atualizadas em tempo real, mantendo-se sempre atualizadas.

As definições mais abrangentes de $\mathrm{CE}$, que incluem o suporte para qualquer tipo de transação de negócio sobre uma infra-estrutura digital, coincidem com o uso mais abrangente que algumas empresas fazem dele, tais como as empresas que utilizam a Web para fornecer informações a seus clientes, como uma ferramenta de marketing, como um canal de vendas e uma linha de suporte, e alguns bancos que utilizam a Internet para as transações de troca de dados financeiros.

A natureza interativa da Internet permite a um vendedor embutir uma série de consultas interativas com seus materiais de mercado, através dos quais eles podem rapidamente determinar as características relevantes e as preferências específicas de um novo cliente, e a existência de mudança nas necessidades de um cliente atual. As ligações de hipertexto permitem uma lógica abrangente e sofisticada, para auxiliar e orientar o comprador a localizar um produto ou serviço específico, para satisfazer suas necessidades.

Em adição, uma vez que os dados estejam coletados, eles podem ser utilizados para atualizar bases de dados de clientes e de marketing, atualizar continuamente os dados internos de marketing, vendas e demanda. Os dados também podem ser utilizados para refinar continuamente os produtos e serviços, permitindo atender um mercado complexo e de constantes mudanças.

A penetração global, o baixo custo e o acesso fácil reduzem drasticamente o custo de comunicar uma mensagem para um mercado potencial bastante grande. Em adição, os filtros eletrônicos e os sistemas de suporte a marketing direto prontos na Internet estão se tornando disponíveis para apoio adicional de recursos direcionados para um vasto mercado global de consumidores.

Atualmente, existem basicamente dois grupos de opiniões e postura sobre o uso de CE. No primeiro, estão as empresas que acreditam 
que a Internet é como a corrida do ouro, quando somente uma empresa vendia um produto específico e seus vendedores ganhavam muito dinheiro, ou ainda aquelas que acreditam que os investimentos na Web devem ser realizados para o futuro e que seu uso não apresenta praticamente nenhum valor no presente.

No segundo, estão as empresas que acreditam que podem obter significativo valor no presente com o uso de CE. Existem vários exemplos de empresas nesse grupo que estão explorando o CE para fins de comunicação entre filiais, conectividade com clientes e fornecedores, propaganda, realização de transações comerciais etc. Essas empresas não têm deixado o ambiente de CE por obterem valor para o seu negócio, o que não acontece no primeiro grupo.

O CE tradicional, através de meios como o EDI, comunicação por fax, tecnologia de símbolos, código de barra, sistema de mensagens interempresas e transferência de arquivos, tem sido um aspecto importante, com o crescimento da tecnologia de informação e de comunicação por vários anos. Entretanto, esse CE tradicional nunca foi tão renovador e teve tanto potencial como o CE na Internet tem se mostrado. ${ }^{14}$

As tecnologias de CE não estão restritas à Internet e à Web, também são consideradas todas as tecnologias de mídia interativa, isto é, a combinação de dispositivos inteligentes e o suporte de dados em multimídia (texto, som, figuras, vídeo etc.), conectados numa rede aberta.

O enfoque inovador e revolucionário do CE pode ser resumido no argumento de que o usual é avaliar uma nova tecnologia num contex to antigo, ou seja, perceber como essa tecnologia permite fazer as coisas atuais de uma maneira diferente. Nesse enfoque, o CE seria considerado como um substituto das maneiras tradicionais de pedir e ofertar mercadorias e serviços. Mas, como cada nova tecnologia, o CE também permite novas possibilidades, impossíveis até então, especialmente pela sua natureza interativa.

\section{Aplicações de comércio eletrônico}

As aplicações atuais de CE nos vários setores econômicos, apesar de crescentes, ainda obedecem uma utilização não-intensiva, que pode ser considerada como exploratória. Além disso, essa utilização não é uniforme nos setores, estando ainda num nível de definições e análise de potencial estratégico e operacional.

Os vários setores, entretanto, têm despendido grande esforço na direção de uma utilização consistente de aplicações de $\mathrm{CE}$, tanto em nível de associações, como das organizações isoladamente.

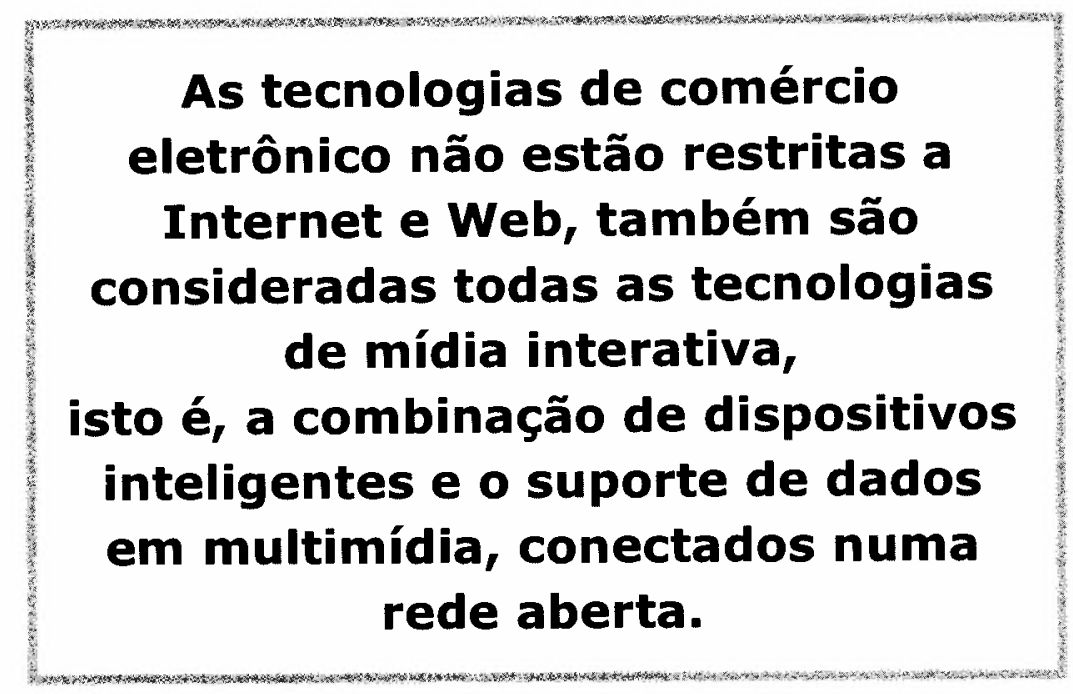

Devido aos vários aspectos envolvidos, sua complexidade inerente a uma mudança de paradigma desse porte e o próprio nível de maturidade da tecnologia e de sua aplicação, as organizações, de uma forma geral, estão concentrando os seus esforços no desenvolvimento de novos canais de distribuição de produtos e serviços existentes. $\mathrm{O}$ desenvolvimento de novos produtos e serviços ainda não pode ser considerado consistente.

\section{Benefícios do comércio eletrônico}

Alguns dos benefícios do CE podem ser entendidos de acordo com estudos e pesquisas de vários autores, entre eles Bloch, Pigneur e Segev. ${ }^{15}$

- Promoção de produtos. Através de um contato direto, rico em informação e interativo com os clientes, o comércio eletrônico pode melhorar a promoção dos produtos.

- Novo canal de vendas. Graças ao seu alcance direto aos clientes e sua natureza bidirecional na comunicação de informação, as aplicações de CE representam um novo canal de vendas para os produtos existentes. Communication of the ACM. v. $39, n .6$, p.23, June 1996.

15. BLOCH M., PIGNEUR, Y., SEGEV, A. On the road of electronic commerce: a business value framework, gaining competitive advantage and some research issue. Lausanne: Institut D'Informatique et Organisation, École des Hautes Etudes Commerciales, Univesité de Lausanne, 1996.
14. PYLE, R. Commerce and the Internet. 
- Economia direta. Utilizando uma infra-estrutura pública compartilhada, tal como a Internet, transmitindo e reutilizando digitalizadamente informação, os sistemas de $C E$ podem reduzir o custo de entrega de informação a clientes e integração eletrônica.

- Inovação de produtos. A natureza baseada em informação dos processos de CE permite que os novos produtos a serem criados ou produtos existentes sejam customizados em maneiras inovadoras. A customização em massa ainda não está sendo de fato utilizada, ela significaria criar produtos específicos para cada cliente, com base nas suas exatas necessidades. Uma outra oportunidade para a customização em massa seria ter o cliente tomando parte do projeto do próprio produto.

- Tempo para comercializar. Com base na sua natureza instantânea, as aplicações de CE permitem reduzir o ciclo de vida da produção e entrega das informações e serviços. No mercado financeiro, o qual muito frequientemente lida com situações em termos de complexidade do ambiente, alguns produtos financeiros têm retorno de investimento em questão de horas.

- Novas oportunidades de negócio. Alterando as estruturas da indústria, as aplicações de CE permitiriam o surgimento de novos modelos de negócios, baseados na ampla disponibilidade de informações e sua distribuição direta aos clientes finais, assim como permitem o surgimento de concorrentes não-tradicionais.

\section{Aspectos do comércio eletrônico}

Algumas das particularidades de sua utilização, estudadas até o momento, são abordadas através dos aspectos relevantes, os quais estão fundamentados em pesquisas recentes e na bibliografia disponível.

\section{Adoção em massa pelo mercado}

A chave para o sucesso das aplicações de $\mathrm{CE}$, certamente, é uma grande adoção desses tipos de tecnologias por parte dos clientes. Não é claro quando isso irá acontecer e, embora haja bastante aprendizagem e benefícios a serem obtidos no presente, a adoção em massa pelo mercado de tais tecnologias poderá levar ainda algum tempo.
Alguns dos fatores que influenciam negativamente essa adoção em massa são: necessidade de infra-estrutura particular, custos envolvidos, objetivo percebido pelo cliente, curva de aprendizagem, resistências pessoais etc.

A resistência a mudanças das pessoas é um dos fatores-chave na adoção de novas tecnologias, assim como a disponibilidade de plataforma tecnológica em todas as residências. O surgimento de computadores de Internet (network computers) de baixo custo e de televisão interativa irá, certa e rapidamente, alterar o mercado.

Assim como na maioria das tecnologias, a adoção está mais ligada com a oferta dos produtos certos do que com a demanda. Isso porque os clientes não-familiarizados com as novas tecnologias não podem definir suas necessidades e irão entender as possibilidades da tecnologia somente através de produtos inovadores.

Cabe mencionar o perigo de examinar os primeiros usuários de qualquer tecnologia, tais como os primeiros usuários de $\mathrm{CE}$, por serem eles sistematicamente diferentes da média dos usuários que surgem mais tarde. Por exemplo, atualmente, as pessoas que usam computadores em casa e serviços on-line orientados para o mercado residencial têm mais habilidade com a tecnologia do que muitos outros segmentos da sociedade.

As transações no ambiente de CE somente podem ter sucesso se as trocas financeiras entre compradores e vendedores poderem acontecer em um ambiente simples, universalmente aceito, seguro e barato. Vários sistemas têm sido propostos, alguns deles baseados em mecanismos transacionais (por exemplo, contas de cartões de crédito), enquanto outros recaem em novos conceitos, tais como dinheiro eletrônico. A chave será encontrar uns poucos mecanismos largamente aceitos, que possam ser utilizados pela maioria dos participantes.

Outro conceito a ser considerado é a necessidade de sistemas mais especializados, por exemplo para permitir microtransações, voltadas para a transferência de quantidades muito pequenas de dinheiro em troca de informações ou serviços. Esse novo mecanismo de pagamento irá permitir novos modelos de negócio, tais como a compra e pagamento de jornal por artigos. 
Finalmente, considera-se que a adoção de uma nova tecnologia está condicionada à percepção do benefício que ela pode trazer ao cliente.

\section{Sistemas eletrônicos de pagamento}

Os sistemas de pagamento eletrônico para consumidores podem ser consideradas desde a década de 40 , e sua primeira aplicação - cartões de crédito - apareceu logo depois. No início da década de 70, a tecnologia de pagamento eletrônico emergente foi denominada de transferência eletrônica de fundos (Electronic Funds Transfer - EFT).

Com o CE, formas inteiramente novas de instrumentos financeiros estão sendo desenvolvidas. Alguns desses novos instrumentos financeiros são relativos aos sinais eletrônicos, na forma de dinheiro ou cheques eletrônicos. Os sinais eletrônicos são projetados como analogias eletrônicas das várias formas de pagamento que têm por trás um banco ou instituição financeira.

Os sinais eletrônicos são de três tipos:

- Dinheiro ou tempo real. As transações são estabelecidas com a troca de moeda eletrônica, por exemplo, o dinheiro eletrônico (e-cash).

- Débito ou pré-pagamento. Os usuários pagam adiantado pelo privilégio de obter informação, por exemplo, os cartões inteligentes que armazenam dinheiro eletrônico.

- Crédito ou pós-pagamento. O servidor autentica os clientes e verifica com o banco se os fundos são adequados antes da compra, por exemplo, os cartões de crédito/débito e cheques eletrônicos ( $e$-check).

O dinheiro eletrônico (e-cash) é um novo conceito nos sistemas de pagamento on-line porque ele combina conveniência computadorizada com segurança e privacidade. $\mathrm{O} e-$ cash precisa ter as seguintes propriedades: valor monetário, interoperabilidade, recuperabilidade, segurança, anonimato e liquidez.

O $e$-cash pode tomar várias formas, incluindo cartões pré-pagos e sistemas genuinamente eletrônicos:

- Cartões pré-pagos. Os compradores podem comprar cartões pré-pagos que são aceitos por vendedores especiais. Atualmente, um dos exemplos de cartão pré-pago é o cartão telefônico, que apresenta a deficiência de não ter liquidez, ou seja, não se pode comprar mer- cadorias com eles. Os cartões inteligentes (smart cards) de múltiplas funcionalidades, anunciados por algumas empresas e que estão, no momento, em teste-piloto, devem incorporar as funções do dinheiro digital.

- Sistemas genuinamente eletrônicos. O dinheiro digital genuinamente eletrônico seria isento da forma física explícita, tornando-se útil para transações em redes e Internet, nas quais o comprador e o vendedor estão em localidades fisicamente remotas. $O$ pagamento seria realizado através de deduções eletrônicas de dinheiro digital do comprador e seguidas de transmissão para o vendedor. A atual transfe-

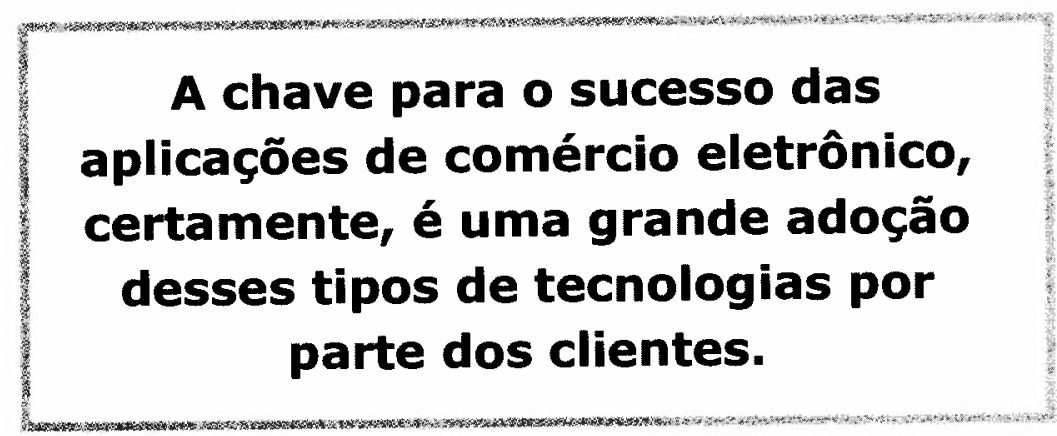

rência de dinheiro digital é usualmente criptografada por sistemas de criptografia de chave pública ou chave privada, de forma que somente o destinatário intencional (o vendedor) possa realmente utilizar o dinheiro. Entretanto, restrições institucionais, como as restrições americanas de exportação de sistemas avançados de criptografia, podem impedir a aceitação e a praticidade do dinheiro digital. Além disso, métodos que assegurem o anonimato precisam estar disponíveis, pois, de outra forma, os sistemas genuinamente eletrônicos não se tornarão alternativas de sistemas de cheque eletrônico.

\section{Privacidade e segurança}

Uma outra fonte potencial de problemas é a preocupação dos clientes com privacidade e segurança, que poderia levar a uma postura contrária aos fornecedores que utilizam tais sistemas, ou simplesmente a não-utilização desses sistemas por parte dos clientes.

Alguns autores acreditam que os clientes são relutantes em fornecer a seus fornecedores os dados referentes a suas informações demográficas, padrões de compras e necessidades de produtos. Infelizmente, esses 
dados são críticos em muitas estratégias, tais como customização em massa, relações com clientes, proatividade etc.

Considera-se que existam duas maneiras de lidar com esses aspectos. A primeira é a conscientização dos clientes em relação aos benefícios de fornecer voluntariamente esses dados (por exemplo, produtos mais aderentes às suas necessidades e redução de correspondências inúteis através de uma maior coerência entre as ofertas comerciais e suas reais necessidades), já a segunda maneira é a oferta de incentivos materiais para atrair os clientes.

Um aspecto amplamente citado dos sistemas on-line atuais é a segurança, apesar de muitos especialistas considerarem-na mais uma questão de percepção do que de realidade. Cabe lembrar que as percepções dos clientes são o que realmente importam em termos de adoção de novas tecnologias.

A segurança dos sistemas on-line tem evoluído muito rapidamente, sendo que novas soluções técnicas têm surgido assim que novas estratégias de CE têm sido implementadas. Dessa forma, a maioria dos sistemas de segurança são suficientes para serem utilizados na maioria das transações comerciais, e a evolução da legislação nesse campo permitirá, progressivamente, o desenvolvimento de melhores sistemas e sua exportação mundial (por exemplo, os sistemas de criptografia com chaves maiores).

Algumas das maneiras pelas quais os problemas de segurança na Internet comercial se manifestam são: bisbilhotice, descoberta de senha alheia, modificação de dados, fraude, não-reconhecimento de transações etc.

Uma solução de segurança robusta para o processamento de transação deve satisfazer os seguintes requerimentos fundamentais de segurança: confiabilidade, autenticação, integridade de dados, impossibilidade de não-reconhecimento, aplicação seletiva de serviços etc.

\section{Relações com clientes}

As primeiras experiências com $\mathrm{CE}$ no setor bancário, o qual tem sido considerado um pioneiro no uso de sistemas eletrônicos, podem ser utilizadas para o aprendizado de alguns perigos potenciais e aspectos a serem considerados.

O uso de ATMs e sistemas de home banking eletrônicos tem permitido progressivamente que os clientes utilizem os serviços bancários fora das agências tradicionais, para a maioria das transações tradicionais. Isso era coerente com a estratégica de economia de custo da maioria dos bancos, os quais descobriram que as transações eletrônicas eram por volta de sete vezes mais baratas, se comparadas com o tratamento manual dessas transações.

O fato de os clientes somente entrarem em contato com seus bancos através de interfaces eletrônicas impedia que os bancos, em muitos casos, vendessem produtos adicionais a seus clientes. A diminuição das interações reais com os clientes podia também levar a um entendimento menos sofisticado de suas necessidades, uma vez que eles nem sempre eram capazes ou estavam dispostos a expressar comentários, críticas e requisitos de novos produtos, enquanto interagindo com máquinas.

Essa situação leva a projetar aplicações de $\mathrm{CE}$ que incorporem oportunidades para compreender os clientes e para a venda proativa de novos produtos. Por um lado, as informações relativas aos clientes devem, através das aplicações de CE, ser mais completas, estar disponíveis e ser mais facilmente tratadas. Por outro lado, o papel do pessoal da agência do banco muda nesse novo ambiente.

Argumentos e experiências similares podem ser encontrados nos outros setores econômicos. $\mathrm{O} C E$ tende a mudar significativamente a relação com os clientes, o que pode ter um efeito positivo ou negativo, dependendo da forma como esse aspecto é tratado.

\section{Aspectos de implementação}

A maioria dos envolvidos com tecnologia acreditam que uma tecnologia sozinha não cria vantagens, mesmo as de CE. A tecnologia precisa ser integrada a uma organização, com os aspectos de gerenciamento de mudanças, relacionados com a resistência das pessoas a novos conceitos e idéias.

$\mathrm{O}$ alinhamento dos componentes de uma organização é considerado como o principal aspecto para estabelecer uma sólida vantagem competitiva. Os aspectos de alinhamento ou equilíbrio relevantes para $\mathrm{CE}$ são aqueles estabelecidos entre: estratégia e tecnologia; tecnologia e os processos organizacionais; e tecnologia e pessoas. 
A importância da aplicação de tecnologia nas estratégias de negócio é amplamente aceita, podendo mesmo ser a chave para diferenciar uma empresa de seus concorrentes. Entretanto, somente a tecnologia não será suficiente para seu sucesso, o nível de serviço oferecido aos clientes e a relação que pode ser estabelecida com eles também poderão ser críticas para evitar a troca de fornecedores por parte dos clientes, ou seja, sustentar sua lealdade.

Existem somente duas maneiras de considerar o alinhamento entre tecnologia e os processos de negócio. A primeira é a necessidade de redefinir alguns processo: após a introdução de aplicações de CE, de moci, que essas aplicaçõ «s tornem-se completamente integradas na maneira pela qual a organização realiza seus negócios.

A outra forma de alinhamento de processos e tecnologia é utilizar a tecnologia para permitir um redesenho dos processos, reduzindo o custo, o tempo e o número de erros associados com o processo, enquanto se eleva o nível de serviço.

Outro fator a ser considerado é o comprometimento organizacional necessário para utilizar com sucesso uma aplicação de CE. Uma aplicação efetiva de tecnologia requer recursos adicionais, em termos de tecnologia e habilidades (por exemplo, projeto profissional, integração de sistemas, integração de processos etc.).

Com grandes participantes presentes no mercado, os clientes se acostumaram a sistemas de alta e progressiva qualidade. As novas tecnologias também aumentam a complexidade do desenvolvimento de uma presença on-line. O custo de um sistema desse tipo é, freqüentemente, muitas vezes maior do que o custo daqueles utilizados para iniciar a participação no mercado ou a utilização dessa tecnologia.

Assim, uma presença sustentada no cyberspace requer um forte comprometimento organizacional para aumentar os recursos alocados para o sucesso e para provar a validade do novo modelo de negócio. Esse comprometimento deverá ser compensado pelo aumento dos retornos financeiros, permitindo justificar os custos adicionais.

Além desses fatores, ainda devem ser considerados aqueles relativos às mudanças organizacionais necessárias, facilitadas e induzidas pelas aplicações de CE, que redefinem desde a estrutura organizacional até os papéis, posturas e responsabilidades.

Finalmente, os fatores relativos aos aspectos legais devem ser considerados, principalmente nas aplicações de CE dos setores tidos como bastante regulamentados.

\section{CONCLUSÃO}

O ambiente empresarial, tanto em nível mundial como nacional, tem passado por profundas mudanças nos últimos anos, as quais têm sido consideradas diretamente relacionadas com a tecnologia de informação. Essa relação engloba desde o surgimento de novas tecnologias, ou novas aplicações, para atender as necessidades do novo ambiente, até o aparecimento de novas oportunidades empresariais criadas pelas novas tecnologias ou novas formas de sua aplicação.

Atualmente, algumas das características do novo ambiente empresarial, tais como globalização, integração interna e externa das organizações, entre outras, têm confirmado as tendências da criação e utilização de mercado e comércio eletrônicos, os quais já são considerados uma realidade.

As organizações devem elaborar, ou pelo menos rever, suas estratégias e operacionalização considerando o comércio eletrônico, buscando assim obter o máximo valor que este pode trazer para o negócio, bem como todos os benefícios de sua utilização. Para tanto, as organizações devem estudar e tratar os vários aspectos relativos ao comércio eletrônịco, sob pena de não aproveitar todo o seu potencial ou mesmo gerar mais impactos negativos do que positivos. 